\title{
Unfavorable Polysomnographic Sleep Patterns Predict Poor Sleep and Poor Psychological Functioning 3 Years Later in Patients with Restless Legs Syndrome
}

\author{
Serge Brand ${ }^{a}$ Johannes Beck ${ }^{a}$ Martin Hatzinger ${ }^{a-c}$ Mirjana Savic ${ }^{a}$ \\ Edith Holsboer-Trachsler ${ }^{a}$ \\ a Psychiatric Hospital of the University of Basel, Depression Research Unit, and b Psychiatric Outpatient Department, \\ University Hospital, Basel, and 'Psychiatric Hospital, Solothurn, Switzerland
}

\section{Key Words}

Restless legs syndrome $\cdot$ Polysomnography $\cdot$ Long-term outcome $\cdot$ Psychological functioning

\begin{abstract}
Background: Amongst the variety of disorders affecting sleep, restless legs syndrome (RLS) merits particular attention. Little is known about long-term outcomes for sleep or psychological functioning following a diagnosis of RLS. The aim of the present study was thus to evaluate sleep and psychological functioning at a 3-year follow-up and based on polysomnographic measurements. Method:Thirty-eight patients (18 female and 20 male patients; mean age: 56.06, $\mathrm{SD}=12.07$ ) with RLS and sleep electroencephalographic recordings were followed-up 33 months later. Participants completed a series of self-rating questionnaires related to sleep and psychological functioning. Additionally, they completed a sleep log for 7 consecutive days. Results: Age, male gender, increased light sleep (S1, S2) and sleep onset latency, along with low sleep efficiency, predicted psychological functioning and sleep 33 months later. Specifically, sleep fragmentation predicted poor psychological functioning, and both sleep fragmentation and light sleep predicted poor sleep. Conclusions: In patients with RLS, irrespective of
\end{abstract}

\section{KARGER}

Fax +41613061234 E-Mail karger@karger.ch www.karger.com
() 2010 S. Karger AG, Basel

0302-282X/11/0632-0092\$38.00/0

Accessible online at:

www.karger.com/nps medication or duration of treatment, poor objective sleep patterns at diagnosis predicted both poor psychological functioning and poor sleep about 3 years after diagnosis. The pattern of results suggests the need for more thorough medical and psychotherapeutic treatment and monitoring of patients with RLS.

Copyright $\odot 2010$ S. Karger AG, Basel

\section{Introduction}

Restoring sleep is strongly associated with daily wellbeing and functioning [1], memory [2,3], emotional intelligence [4], learning capacity, and academic performance [5]. By contrast, chronic sleep disturbances adversely affect physical and psychological functioning in both adolescents [6] and adults [7, 8]. Furthermore, sleep complaints and insomnia in adults seem to be on the increase worldwide $[9,10]$.

Amongst the variety of possible factors adversely affecting sleep, restless legs syndrome (RLS) has been described as 'the most common disorder you ever heard of' [11]. RLS is a distressing sensorimotor disorder. An alteration of iron-dopamine connections $[12,13]$ as well as genetic factors [14] have been implicated in its etiology.

Psychiatric Hospital of the University of Basel, Depression Research Unit, Switzerland Wilhelm Klein-Strasse 27

$\mathrm{CH}-4025$ Basel (Switzerland)

Tel. +41 6132551 14, Fax +41 6132555 13, E-Mail serge.brand@ upkbs.ch 
For several reasons, RLS demands particular attention. First, prevalence rates range from 5 to $10 \%$ in the United States and other Western countries $[15,16]$. Second, RLS does not only affect adults: it is also observed in children and adolescents [17-19]. Third, RLS is associated with a broad variety of additional psychiatric disorders. Several studies have reported the co-occurrence of RLS and depressive symptoms [11, 18, 20-26]. In particular, patients suffering from RLS have shown poor polysomnographic sleep patterns, compared both to healthy controls [27] and patients suffering from major depressive disorders $[25,26]$. In this respect, Hornyak et al. [26] observed that several antidepressants may trigger or aggravate RLS. By contrast, mild to moderate depressive symptoms often seem to be relieved, with improvements in RLS symptoms, after administration of dopamine receptor agonists. Furthermore, $83.3 \%$ of the patients with dysthymia, $63.6 \%$ of those with general anxiety disorders, and $60 \%$ of those with panic disorder reported the occurrence of RLS before the onset of the psychiatric disorder [24]. Recent findings from a population-based survey in South Korea suggest that the prevalence of RLS there may be substantially lower than in Western countries, though the occurrence of RLS was strongly associated with major depressive disorders, panic disorders, and posttraumatic stress disorder [28].

The occurrence of RLS is associated with poor quality of life and with particular personality traits. Happe et al. [29], for example, assessed 519 patients suffering from RLS in a cross-sectional study and observed that healthrelated quality of life was substantially affected, compared to indices for the general population. Severity of RLS and depressive symptoms had the most significant influence on deteriorated health-related quality of life. Likewise, a series of cross-sectional studies have identified poorer quality of life and psychological functioning among patients suffering from RLS as compared to controls [for a comprehensive overview, see ref. 29]. In a similar vein, based on the 5 -factor model of personality proposed by Costa and McCrae [30], Kalaydjian et al. [31] investigated differences in personality traits between patients suffering from RLS and controls. The results showed significant differences on neuroticism, but not on openness, agreeableness, conscientiousness, or extraversion, i.e., compared to controls, patients suffering from RLS had higher scores for anxiety, anger/hostility, and depression.

Long-term treatment outcomes of RLS have focused exclusively on the impact of medication [32-38], though with conflicting results: whereas some studies have re- ported a marked decrease in RLS [37] and exceptional efficacy for RLS-related medication [32], others have reported either increased severity of symptoms [35] or only symptomatic relief rather than any curative effect [32]. However, nothing is known about the extent to which polysomnographic sleep patterns may predict long-term development of sleep or psychological functioning in patients with diagnosed RLS. The aim of the present study was thus to relate sleep electroencephalographic (EEG) values to self-reported sleep and psychological functioning about 3 years later.

Since specific long-term data have not been available until now, no hypotheses were formulated. As a consequence, an exploratory approach was adopted.

\section{Methods}

Sample and Procedure

A sample of 63 patients (30 females and 33 males) was diagnosed in our Sleep Research Unit between April 2001 and October 2005 (mean age 51.76 years, $S D=15.34$ ) [25]. At first contact, a thorough assessment was made, including a brief psychiatric interview, diagnosis of RLS, and polysomnographic EEG recordings. These patients were subsequently recontacted, the follow-up occurring on average 33 months later $(\mathrm{SD}=13.28$; range $18-63$ months). The response rate was $61 \%$ (38 participants ${ }^{1}: 18$ female $(47.5 \%)$ and 20 male $(52.5 \%)$ patients; mean age 55.32 years, $\mathrm{SD}=$ 12.33) $)^{2}$

Patients were contacted by telephone and asked to participate in a follow-up study consisting of a set of questionnaires (see below) concerning current sleep, quality of life, medication intake and psychological functioning. The purposes of the study were fully explained. Participants received the questionnaires and the informed consent by mail. All participants received a reward of CHF 40.00 for participation. The experimental protocol was approved by the local ethics committee.

\section{Materials}

Initial Assessment of Sleep by Polysomnography

All patients slept in the Sleep Research Unit for one night. Sleep was recorded between 11 p.m. (lights off) and 7 a.m. (lights on) using standard polysomnography procedures, namely a horizontal electrooculogram, a submental myogram and an EEG recording: C3-A2, C4-A1, C3-C4) as well as an electrocardiogram. The sleep records were visually scored by two experienced raters

\footnotetext{
1 Of the 25 nonparticipants, 2 had died, 6 were hospitalized, 7 could not be contacted, and 10 refused to participate due to lack of interest or time. 2 Participants at follow-up did not differ from nonparticipants with respect to gender distribution (participants: male:female $=18: 20$; nonparticipants: male:female $=12: 13 ; \chi^{2}(1)=0.002, \mathrm{p}=0.961$ ), age (participants: 55.32 years $(\mathrm{SD}=12.33)$; nonparticipants: 57.67 years $(\mathrm{SD}=10.21)=\mathrm{t}(61)=$ $0.65, \mathrm{p}=0.52$ ), or initial sleep EEG profiles (all ts $<1$ ). Thus, there was no systematic bias between participants and nonparticipants.
} 
Table 1. Dimensions of FEPS I and II

\begin{tabular}{|c|c|c|}
\hline \multirow[t]{2}{*}{ Dimensions } & \multicolumn{2}{|l|}{ Poles } \\
\hline & positive pole & negative pole \\
\hline \multicolumn{3}{|l|}{ FEPS I } \\
\hline Attitude towards life & Satisfied, confident, positive & Depressive, dissatisfied, resigned, lacking emotion \\
\hline Self-confidence & Self-confident, resolute, carefree & Anxious, unsure, indecisive, easily irritated \\
\hline Mental arousal & Relaxed, balanced, calm & Tense, irritable, exhausted, burdened \\
\hline Physical arousal & Relaxed, balanced, without any complaints & Nervous, over-agitated, complaining \\
\hline Aggressive behavior $^{1}$ & Externalizing, competitive, asserting own opinion & Internalizing, over-controlling, inhibited, evasive \\
\hline Self-perception of body sensations & Easy-going, carefree, confiding & Hypochondriac, complaining \\
\hline Subjective sleep quality ${ }^{2}$ & Regenerative, undisturbed, unimpaired & Impaired, disturbed, not regenerative \\
\hline \multicolumn{3}{|l|}{ FEPS II } \\
\hline Focusing & Easy-going, carefree, confiding with regard to sleep & $\begin{array}{l}\text { Concerned about sleep; preoccupied about not falling } \\
\text { asleep, not sleeping enough to feel restored }\end{array}$ \\
\hline Rumination & Optimistic about coping with problems & Concerned and preoccupied about unresolved problems \\
\hline
\end{tabular}

according to standardized criteria [39]. Twenty percent of the sleep records were independently rescored. Inter-rater reliability was $r=0.92$. The sleep parameters were analyzed according to the definitions in the standard program described by Lauer et al. [40; also see ref. 25] ${ }^{3}$.

\section{Assessments at Follow-Up}

Depressive Symptoms

Participants completed the Beck Depression Inventory [41] providing self-rating of depressive disorders. The higher the overall score, the more the respondent is taken to suffer from depressive symptoms (Cronbach's $\alpha=0.89$ ).

\section{Restless Legs Syndrome}

Following the International RLS Study group [42], a diagnosis of RLS is given if patients answer 'yes' to the following 6 questions: (1) symptoms of leg restlessness; (2) unpleasant creepy/crawly feelings in the legs; (3) co-occurrence of leg restlessness and unpleasant feelings in the legs; (4) occurrence of these feelings mainly at rest, (5) improvement with movement, and (6) worsening of these sensations in the evening or at night as compared to the morning [43; Cronbach's $\alpha=0.88$ ].

\section{Sleep Disturbances}

Five items were taken from the Insomnia Severity Index [44; Cronbach's $\alpha=0.90]$. (1) To assess insomnia, participants were asked the following questions: 'In the last two weeks, how much did you suffer from the following disturbances: difficulty falling asleep, difficulties maintaining sleep, early morning awakening,

3 With respect to the medication during polysomnographic assessment, as in the former study [25], no systematic bias between sleep-altering and non-sleep-altering medications on sleep EEG profiles was observed. increased daytime sleepiness?' Answers were given on a 5-point rating scale ranging from $0=$ 'not at all' to $4=$ 'very much'. (2) 'How satisfied are you with your sleep?' Answers were given on a 5 -point scale ranging from $0=$ 'very satisfied' to $4=$ 'very dissatisfied'. (3) 'How much does sleep disturbance have a negative impact on your daily performance?' Answers were given on a 5 -point scale ranging from $0=$ 'not at all' to $4=$ 'very much'. (4) 'How much do you think that other people are aware that your sleep disturbance negatively influences your daily performance?' Answers were given on a 5-point scale ranging from $0=$ 'not at all' to 4 = 'very much'. (5) 'How much are you actually worried about your sleep disturbance?' Answers were given on a 5-point scale ranging from $0=$ 'not at all' to $4=$ 'very much'. The higher the mean score, the more the person is assumed to suffer from insomnia. This mean score was labeled 'Insomnia Severity'.

Sleep-Related Personality Traits

Participants also completed a single sleep-related personality questionnaire, i.e. a questionnaire specifically designed to assess personality traits of patients with sleep complaints (Fragebogen zur Erfassung allgemeiner Persönlichkeitsmerkmale $\underline{\text { Schlaf- }}$ gestörter; Questionnaire for Assessing General Personality Traits of Patients Suffering from Sleep Disorders; FEPS-I and II) [45; Cronbach's $\alpha$ for internal consistency for both FEPS I and II = 0.89]. The FEPS-I questionnaire consists of 64 items describing 6 sleep-related personality traits and subjective sleep quality. Answers are given on a 5-point scale ranging from 'is not true at all' to 'is completely true'. The dimensions are presented in table 1. The underlying rationale for these two dimensions is that dysfunctional, or negative cognitions such as continually worrying about not being able to sleep or about unresolved problems are the main factors in the development and persistence of sleep problems [45-47]. The sleep-related personality questionnaire was chosen because it has been shown to be suitable both for patients suffering from sleep disorders and for healthy subjects [45, 48, 49]. 


\section{Daily Sleep Log}

The sleep log was based on the Pittsburgh Sleep Quality Index [50] the German adaptation of which was taken from a conventional and widely used manual for psychological treatment of sleep complaints [51]. In contrast to this index, the adapted sleep log was completed consecutively. Participants were asked to fill it out twice a day for a week - in the evening and in the morning. In the evening, participants responded to questions about daytime sleepiness $(1=$ 'high daytime sleepiness'), physical activity $(1=$ 'low physical activity'), concentration (1 = 'low concentration'), and mood ( 1 = 'very bad mood') on 8-point scales. In the morning, the questionnaire asked about sleep quality ( 1 = 'very bad sleep quality'), mood (1 = 'very bad mood'), using the same scales. In addition, sleep onset latency (SOL, in minutes), awakenings after sleep onset (number), and total sleep time (in hours) was requested (Cronbach's $\alpha=0.89$ ). Nights were defined as weekday nights if the participant went to work the following day; accordingly, weekend nights were Friday and Saturday nights. Two separate composite variables were calculated for weekdays and weekend days, respectively.

\section{Assessment of Current Medication}

Participants were asked to record any current medications. In particular, they were asked whether they were currently taking any medications relating to RLS or depressive symptoms. Medications were labeled as follows: medication 1 (antidepressants, such as mirtazapine, duloxetine, trimipramine, 'yes' vs. 'no'), medication 2 (RLS-related medications, such as pramipexole, gabapentine, ropinirole, 'yes' vs. 'no'), and medication 3 (benzodiazepines, such as midazolame, diazepame, clonazepame, 'yes' vs. 'no').

\section{Assessing Quality of Life}

The Skala zur Erfassung der Lebensqualität (Scale for the Assessment of Quality of Life, SEL) [52] was administered to assess quality of life. The questionnaire consists of 67 items and assesses current mood (e.g. 'At the moment, I feel abysmal'), objective and subjective physical state (e.g., for objective, 'I have difficulties or I have observed changes in the heart and lungs, such as shortness of breath, heart irregularity; for subjective, 'Over recent weeks, I have had a lot of pain'), objective and subjective social environment (e.g., for objective, 'I wish I had more people to share my sorrows with'; for subjective, 'Over the last weeks, it has been comforting to talk to my family'), global mood (e.g. 'Over the last weeks, I have been quite happy') and orientation to life (e.g. 'I think that also in the future I'll have many interesting things to do'). Answers are given on a 5-point rating scale ranging from 1 (= not at all true) to 5 (= definitely true; scoring was reversed for some items). For the dimensions Mood, Subjective social environment, Global attitude, and Orientation to life, higher mean scores reflect a favorable position on the dimension. For the dimensions Objective physical state, Subjective physical state, and Objective social environment, higher mean scores reflect an unfavorable position on the dimension.

\section{Statistical Analyses and Preliminary Computations}

First, to compress and reduce the psychological functioning outcome variables [Beck Depression Inventory (BDI), SEL, FEPS I and II], a factor analysis was performed with orthogonal rotation [53]. A factor analysis of 16 items from the BDI (total sum score), the questionnaires related to quality of life (SEL) and to sleep-re- lated personality traits (FEPS I and II) yielded 15 factors. The first 3 had eigenvalues greater than 1, together accounting for $78.4 \%$ of the overall variance. The first factor, with an eigenvalue of 8.48 , labeled 'Psychological arousal and depressive symptoms', explained $56.53 \%$ of the total variance. The second factor, labeled 'External locus of control and rumination' (eigenvalue 1.97), explained $13.14 \%$ of the total variance. The third factor, labeled 'Social withdrawal and low social support' (eigenvalue 1.29) explained $8.66 \%$ of the overall variance. The term 'Psychological functioning' embraces the dimensions 'Psychological arousal and depressive symptoms', 'External locus of control and rumination', and 'Social withdrawal and low social support'.

Next, to compress and reduce the results extracted from the sleep log, a factor analysis with orthogonal rotation was again performed. The factor analysis of 9 variables yielded 8 factors; the first 3 had eigenvalues higher than 1, together accounting for $84.50 \%$ of total variance. The first factor, labeled 'Sleep quality and sleep-related mood and behavior' (eigenvalue 5.56) explained $59.28 \%$ of the total variance. The second factor, labeled 'Sleep duration and sleep fragmentation' (eigenvalue 2.13) explained $17.24 \%$ of the total variance. The third factor, labeled 'Sleep onset latency' (eigenvalue 1.09) explained 7.98\% of the overall variance.

Next, the influence of possible confounding variables was examined. To this end, a series of multiple-regression analyses (excluding stepwise backwards) were performed with the 6 new factors identified above as dependent variables whereas the possible confounding variables were identified as independent variables. Possible confounding variables considered were age, gender, difference in years between first assessment and follow-up (termed 'RLS duration'), medication 1 (antidepressants 'yes' vs. 'no'), medication 2 (RLS-related medicaments 'yes' vs. 'no'), and medication 3 (benzodiazepines 'yes' vs. 'no'). It turned out that for all 6 multiple regression analyses, age, gender, and 'RLS duration' were of predictive value whereas this was not the case for the variables related to medications. Thus, medications were not introduced as covariates.

Next, we examined whether current medication was in any way related to former sleep EEG profiles and whether medications should thus have been introduced as a factor confounding the relation of sleep EEG variables and current sleep patterns and psychological functioning. To this end, an ANOVA with the factors medication 1, medication 2, and medication 3 and the sleep EEG profiles as dependent variables was performed. Current medication was found to be unrelated to former sleep EEG profiles (all Fs $<1.2$ ). Thus, current medication was not introduced as a possible confounding factor between former sleep EEG profiles and current sleep patterns and psychological functioning.

Last, to predict psychological functioning at follow-up ('Psychological arousal and depressive symptoms'; 'External locus of control and rumination'; 'Social withdrawal and low social support'), sleep at follow-up ('Sleep quality and sleep-related mood and behavior', 'Sleep duration and sleep fragmentation'; 'Sleep onset latency'; 'Insomnia Severity'), and occurrence of RLS at followup, a series multiple-regression analyses were performed with age, gender, RLS duration and the sleep variables derived from polysomnographic sleep recordings as predictors.

Pearson correlations were computed and analyses were conducted using SPSS 17.0 for Windows. 
Table 2. Multiple linear regression models to describe the influence of age, gender, duration to follow-up, and objective sleep on psychological functioning

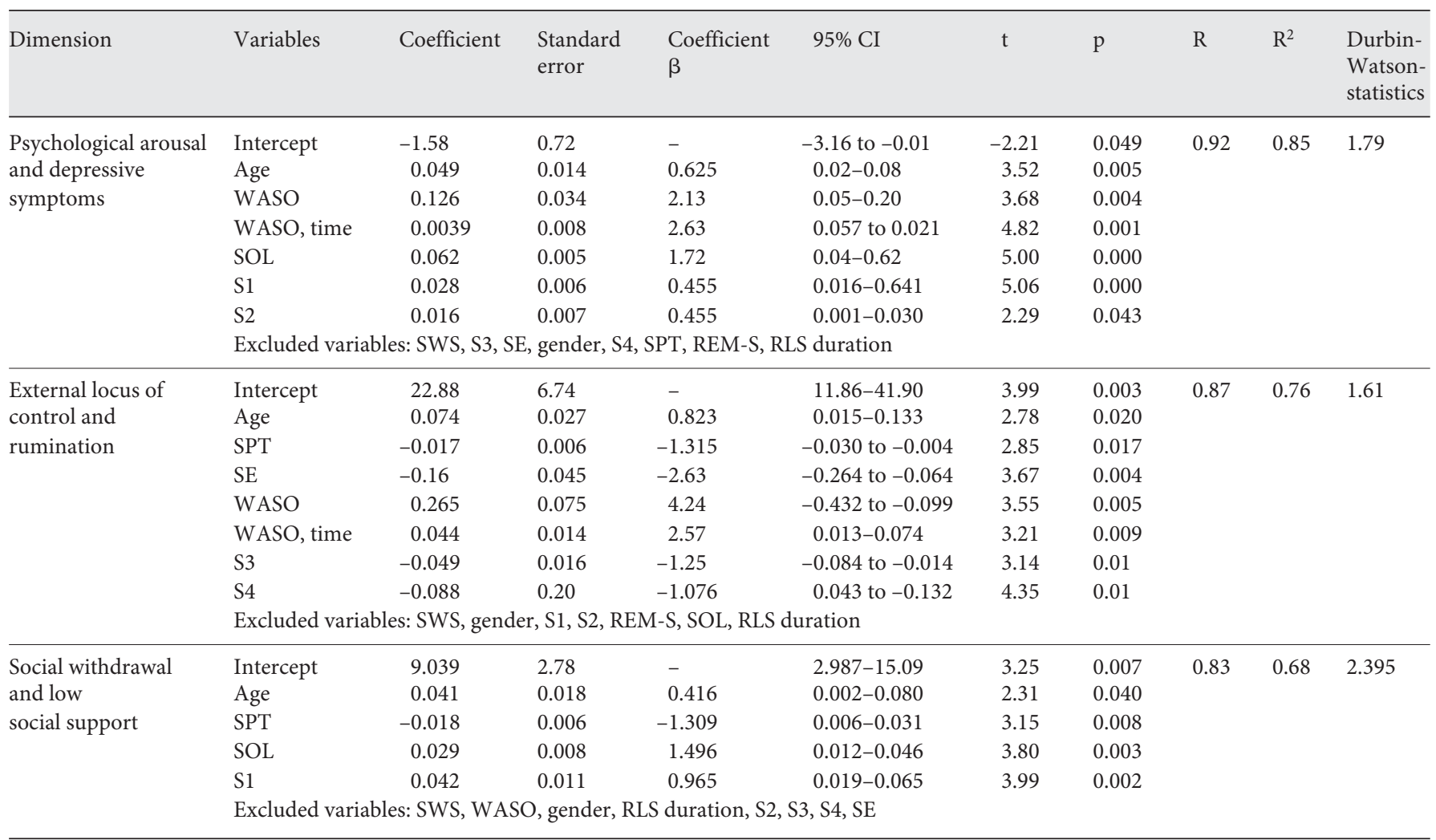

SOL = Sleep onset latency; SPT = sleep period time; S1 etc. = stage 1 etc.; WASO = wakening after sleep onset; light sleep $(\mathrm{min})=\mathrm{S} 1+\mathrm{S} 2 ;$ slow-wave sleep $(\mathrm{min}) \mathrm{SWS}=\mathrm{S} 3+\mathrm{S} 4$; REM-S = REM sleep; $\mathrm{SE}=$ sleep efficiency; $\mathrm{CI}=$ confidence interval; $\mathrm{R}=$ multiple correlation coefficient; $\mathrm{R}^{2}=$ multiple coefficient of determination.

\section{Results}

\section{Predicting Psychological Functioning}

Table 2 summarizes the multiple-regression analyses with Psychological functioning as outcome variable and age, gender, RSL duration, and polysomnographic EEG variables as predictors.

Increased psychological arousal and depressive symptoms were predicted by greater age, more awakenings after sleep onset (amount and duration), a prolonged SOL, and increased light sleep (S1 and S2). Greater external locus of control and rumination were predicted by lower age, decreased sleep period time and sleep efficiency, more awakenings after sleep onset (number and duration), and shortened SWS (S3 and S4).

More marked social withdrawal and lower social support were predicted by greater age, shortened SPT, a prolonged SOL, increased S1 and decreased S4.
Taken together, along with age, both an increased sleep fragmentation and increased light sleep predicted poor psychological functioning about three years later.

\section{Prediction of Sleep}

Table 3 gives an overview of the multiple regression analyses with Sleep (as extracted from the daily sleep log) as outcome variable and age, RLS duration, gender, and polysomnographic EEG variables as predictors.

Poorer sleep quality and sleep-related mood and behavior were predicted by prolonged RLS duration, male gender, lower age, an increased sleep fragmentation, along with increased light sleep (S1, S2), decreased S4, and increased rapid eye movement (REM)-sleep. Shortened Sleep duration and increased sleep fragmentation were predicted by increased RLS duration, male gender, more awakening after SO (sleep onset; number and duration), increased light sleep (S1, S2), decreased S4, and increased 
Table 3. Multiple linear regression models to describe the influence of objective sleep, age, and gender on subjective sleep from the daily sleep log

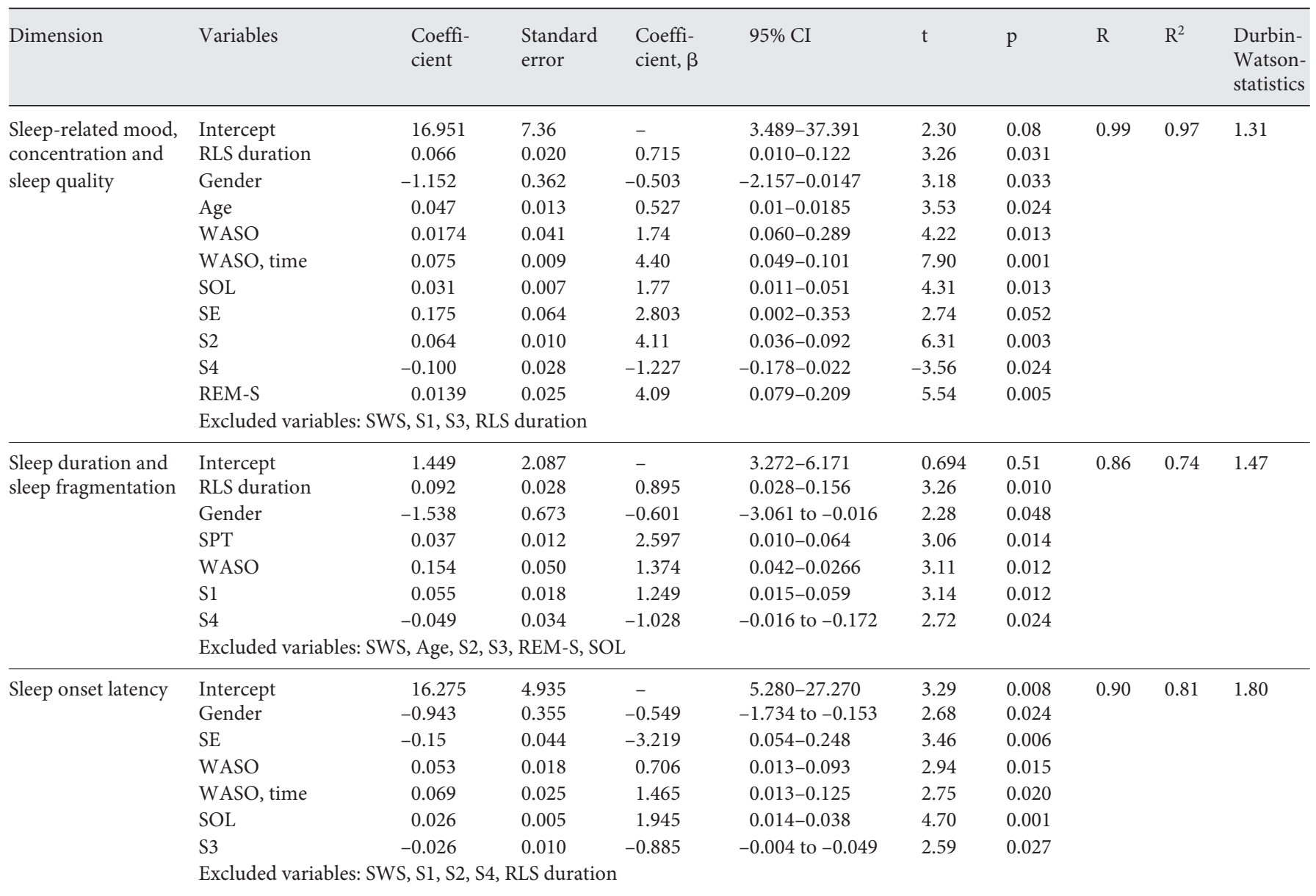

$\mathrm{SOL}=$ Sleep onset latency; WASO = wakening after sleep onset; light sleep $(\mathrm{min})=\mathrm{S} 1+\mathrm{S} 2$; slow wave sleep $(\mathrm{min}) \mathrm{SWS}=\mathrm{S} 3+\mathrm{S} 4 ; \mathrm{REM}-\mathrm{S}=\mathrm{REM}$ sleep; $\mathrm{SE}=$ sleep efficiency; $\mathrm{S} 1$ etc. $=$ Stage $1 ; \mathrm{CI}=$ confidence interval; $\mathrm{R}=$ multiple correlation coefficient; $\mathrm{R}^{2}=$ multiple coefficient of determination .

REM-sleep. A prolonged SOL was predicted by age, female gender, reduced SE, increased wakening after sleep onset (amount and duration), a markedly prolonged SOL, and shortened S3. In sum, poor sleep as extracted from the sleep log was predicted by gender, age, RLS duration, and by fragmented sleep, increased light sleep and decreased deep sleep.

\section{Prediction of Occurrence of RLS, Depressive}

Symptoms, and Sleep Complaints at Follow-Up

Further computations showed that at follow-up, RLS, depressive symptoms (BDI sum score) and sleep complaints (sum score, Insomnia Severity Index, ISI) were intercorrelated; RLS, BDI; $\mathrm{r}=0.47, \mathrm{p}<0.001$; RLS, ISI: $\mathrm{r}=$
0.59, $\mathrm{p}<0.001$; BDI, ISI: $\mathrm{r}=0.77, \mathrm{p}<0.001$. Thus, the question arose as to whether polysomnographic sleep variables could predict RLS, depressive symptoms, and sleep complaints. Multiple regression analyses with the polysomnographic variables as predictors and the occurrence of RLS, depressive symptoms (sum score BDI) and sleep complaints as dependent variables showed that neither the polysomnographic sleep variables as a whole, nor specific polysomnographic sleep variables were of predictive value. R's and $\mathrm{R}^{2}$ 's were between 0.75 and 0.85 , though ANOVAs revealed that multiple correlation coefficients did not significantly differ from $0(\mathrm{p}>0.1)$. Thus, polysomnographic values could predict neither RLS, nor depressive symptoms, nor sleep complaints. 


\section{Discussion}

The key findings of the present study are that greater age, polysomnographically assessed increased light sleep and decreased deep sleep, along with sleep fragmentation, could predict poor sleep and poor psychological functioning of patients with diagnosed RLS about three years after diagnosis. Moreover, RLS duration and medication did not alter the pattern of results.

Given the lack of long-term studies focusing on sleep and psychological functioning as a function of previously assessed objective sleep profiles in patients suffering from RLS, no specific hypotheses were formulated. In this respect, to our knowledge, only a few studies have focused on long-term outcomes of psychiatric disorders based on polysomnographic recordings at baseline. Hatzinger et al. [54] followed up 15 patients suffering from major depressive disorders. At follow-up, about three years later, both sleep-EEG recordings and the activity of the hypothalamus-pituitary-adrenocortical (HPA) axis were assessed. Results suggested that decreased slow wave sleep (SWS) variables especially in the first sleep period and increased REM density were predictive for the occurrence of depressive symptoms at follow-up. Additionally, these unfavorable sleep-EEG variables were also related to excessive stress hormone response in the DEX/CRH-test. In sum, unfavorable sleep patterns such as decreased SWS and increased REM density were predictive of unfavorable outcomes of depressive disorders 3 years later. By contrast, in our study, REM sleep was of no predictive value. Rather, an entire set of specific sleep patterns relating both to sleep architecture (increased light sleep; decreased deep sleep) and sleep continuation (sleep fragmentation), along with age and gender, was associated with unfavorable sleep and psychological functioning at follow-up. With respect to gender, no clear picture emerged: some unfavorable outcomes were associated both with being male and with being female.

Long-term studies of RLS treatment outcomes have focused primarily on effects of medication [32-38], but the findings have been inconsistent. Whereas some studies have reported a marked decrease in RLS [37] and outstanding efficacy of RLS-related medication [32], others have reported an increase in symptoms [35], or only symptomatic relief rather than any curative effect [32]. The results of our study are in line with those reporting more negative findings [32]. Importantly, as our data suggest, the presence or absence of medications for RLS, depression or sleep difficulties (i.e. benzodiazepines) had no impact on outcomes related to sleep or psychological functioning about 3 years later.

The present data do not allow a closer inspection of the specific regimen pursued by every single patient. Thus, the data do not provide information on who took what compound for how much time at what level of compliance or at what dosage. However, notwithstanding the lack of these details, the overall pattern supports the speculation that patients' compliance was mixed given that medication-based treatment was recommended after the diagnosis of RLS. Moreover, statistical computations indicated that the current medication did not systematically bias either former sleep EEG variables or current sleep patterns and psychological functioning. How should one explain a presumably mixed or unsatisfactory level of compliance? First, there is increasing evidence that antidepressants such as fluoxetine and selective serotonin reuptake inhibitors (SSRIs) may increase periodic leg movements and, consequently, also RLS [for detailed discussions, see ref. 22, 26, 41, 55, 56]. However, in this respect, recent findings suggest that the occurrence and duration of SSRI-induced RLS and periodic leg movements are more complex [56]. Second, recent findings suggest an association between olanzapine and RLS [57]. Third, both medication tolerance and augmentation effects are well-known unwanted, though common side effects [5860]. Summing up, one may speculate that patients did alter (increase, reduce, interrupt, and/or quit) the regimen, either independently or after consultation with their physician, though for unknown reasons and with unsatisfactory outcomes.

However, the pattern of results ('poor sleep predicts poor sleep and poor psychological functioning') is not necessarily specific to the development of RLS. Rather, our results fit well with a wealth of long-term research related to sleep and psychological functioning. Roberts et al. [6] found that chronic insomnia in adolescents severely impacted upon physical and psychological health over a 12-month period. In a population-based survey of adults, Morphy et al. [7] found that the incidence of insomnia at 12 months was $15 \%$ among those without insomnia at baseline and that this was significantly associated with baseline anxiety, depression, and pain. More importantly, of those who did have insomnia at baseline, $69 \%$ had insomnia at the 12-month follow-up, suggesting that insomnia is a persisting disorder. Likewise, Leblanc et al. [8] showed that a 1-year insomnia incidence rate was high and several psychological and health factors were associated with new-onset insomnia. Specifically, compared to good sleepers, insomnia syndrome incident cas- 
es presented with premorbid psychological vulnerability to insomnia, characterized by more marked symptoms of depression and anxiety, lower extraversion, higher arousability, and poorer self-rated mental health at baseline. These patients also presented with a higher level of bodily pain and poorer general health. Importantly, this pattern of results indicates that sleep and psychological functioning are highly interrelated. Taken together, findings from longitudinal studies show that poor sleep and poor psychological functioning do persist over time. As our data suggest, this also holds for patients with RLS.

However, the question arises as to why patients suffering from RLS should show a similar pattern of results even 3 years after diagnosis. The present data do not allow a conclusive answer to be drawn. However, the following observations should be taken into account. First, poor sleep, almost by definition, is strongly associated with depressive disorders [54], pain [61-64], and somatoform disorders [65]. Thus, it is highly conceivable that disrupted sleep as a consequence of RLS had resulted in poor psychological functioning. Second, another longitudinal study suggests that depressive disorders may lead to poor sleep, which in turn may lead to depressive disorders, and that poor sleep and depressive disorders may co-occur without common etiology [66]. The observations made the present study may speculatively be explained by a similar pattern of interrelated perturbations. Furthermore, although again speculative, rather than a static if-then relation between poor sleep and poor psychological functioning, a more dynamic process is conceivably at work. As an illustration, the model of Patterson et al. [67] for the development and maintenance of children's coercive behavior proposes that adverse parenting styles such as high behavioral and responsive inconsistency, low control and lack of warmth exacerbate an unfavorable childhood temperament (e.g. easily irritable, irascible, low tolerance of frustration), negative behavior (e.g. oppositional-aggressive, hyperactive), and poor intellectual skills (e.g. low degree of fast and accurate information processing), and vice versa. Thus, this model claims a reciprocal impact and feedback loop between the parents' style and the child's psychosocial, intellectual and behavioral characteristics over time. Similarly, we may speculate that, over time, poor sleep (due to RLS) may lead to poor psychological functioning, and that poor psychological functioning may aggravate poor sleep in a process of reciprocal interaction.

It is of note that sleep EEG recordings predicted neither the degree of RLS, nor depressive symptoms (BDI) or sleep complaints (ISI). How should this pattern of re- sults be interpreted? We think there are five possibilities. One is that the current state of RLS, depressive symptoms, and sleep complaints may be affected by other factors, such as current medication (treatment effects) and use of substances (caffeine, alcohol), and that these factors therefore act as confounds between sleep EEG data at the sleep-EEG assessment and state at follow-up 33 months later. A second possibility is that objective measures and subjective sensations and perceptions may not necessarily correspond. Third, it may be that the disease process of RLS, which is primarily a peripheral movement disorder, is spreading and influencing neural networks and thus sleep and psychological functioning. Fourth, other dimensions related to sleep and psychological functioning, though not assessed in this study, were confounding covariates. The fifth possibility is that there really is no association.

Despite the new findings, several considerations warrant against generalization, and these data should be interpreted cautiously. First, the medication intake between the first sleep EEG assessment and the follow-up, and the possible influence of the medication regimen on the current data, remain unclear. However, to tackle this issue, we examined the possible confounding effect of current medication both on former sleep EEG variables and on current psychological functioning and sleep. It appeared that current medication did not systematically influence the data. It therefore seems likely that current medication was of minor importance. Second, the time lapse between the first and the second assessment showed a high interindividual range, which may have led to a biased pattern of results. To tackle this issue, the interindividual difference between the first and the second assessment (termed 'RLS duration') was introduced as a possible confounding variable; as the pattern of results suggests (tables 2,3), the time lapse between the first and the second assessment was not a confounding variable. Moreover, in our opinion, the large interindividual differences in the time lapse provide a compelling reflection of both the strengths and the difficulties of naturalistic studies conducted under clinical routine conditions. As a result, long-term observations are rare, though, in our view, they are of considerable practical relevance. Third, data at follow-up relating to psychological functioning were based on self-reports, and it is possible that an increased state of depression may have biased the pattern of response behavior. Thus, any future investigations should employ experts' ratings and a clinical psychiatric interview as well as a thorough physical examination. Though somatic complaints were covered in the questionnaire related to quality of life [52], it is con- 
ceivable that somatic complaints not assessed thus far may have negatively influenced current psychological functioning. Fourth, Pearson et al. [68] observed that, in patients suffering from RLS, cognitive performance was decreased compared to controls; thus, it is possible that the pattern of response behavior may have been biased by $\operatorname{cog}$ nitive impairments. Fifth, sleep patterns were gathered from subjective sleep reports and not from objective sleep registrations such as sleep EEGs or actigraphy, and again a rating bias cannot be excluded. However, the sleep log was completed consecutively rather than retrospectively; thus, this procedure does not heavily rely on memory and is therefore less susceptible to memory failure. Moreover, there is evidence that diary-reported sleep patterns may be as valid as actigraphically estimated sleep behaviors $[69,70]$. Additionally, we have been able to show that subjective sleep data from sleep logs provide a good match with sleep EEG recordings [71, 72]. Sixth, no objective assessment of RLS was performed; this may be of particular concern because recent findings suggest that adding response to dopaminergic medication improved the accuracy of RLS diagnosis, that is, the risk of mimics was reduced [73]. Seventh, data may potentially be biased because only patients who were willing and able to complete the questionnaires and the daily sleep log for 7 consecutive days volunteered to participate in the study. Last, the time lag of about 3 years between diagnosis and follow-up is not necessarily comparable to a period of therapy.

\section{Conclusion}

In patients with RLS, poor objective sleep almost 3 years earlier predicted current poor sleep and psychological functioning. Moreover, medication regimen seemed to have no influence, either favorable or unfavorable. As a consequence, we propose that an accurate thorough treatment consisting both of psychotherapy and medication is needed. In this view, one may claim that disorders such as RLS are not as easy to treat as it seems, and that monitoring should therefore be performed by specialized sleep centers throughout rather than by residents.

\section{Acknowledgements}

We thank Alexandre Mueller and Martin Walde for data entry. We also thank Nick Emler (Surrey, UK) for proofreading the manuscript. Furthermore, we thank Lundbeck (Switzerland) for the financial support in the form of an unrestricted grant (S.B.).

\section{Conflict of Interest}

Lundbeck had no influence on the study project; particularly, the sponsor had no influence on data collection, data entry, data analyses, data interpretation or writing and submission of the manuscript, or selection of the journal for possible publication. All authors declare no conflicts of interest.

\section{References}

1 Banks S, Dinges DF: Behavioral and physiological consequences of sleep restriction. J Clin Sleep Med 2007;3:519-528.

-2 Stickgold R, Walker MP: Sleep-dependent memory consolidation and reconsolidation. Sleep Med 2007;8:331-343

3 Walker MP: The role of sleep in cognition and emotion. Ann NY Acad Sci 2009;1156: 168-197.

\4 Killgore WD, Kahn-Greene ET, Lipizzi EL, Newman RA, Kamimori GH, Balkin TJ: Sleep deprivation reduces perceived emotional intelligence and constructive thinking skills. Sleep Med 2008;9:517-526.

5 Curcio G, Ferrara M, De Gennaro L: Sleep loss, learning capacity and academic performance. Sleep Med Rev 2006;10:323-337.

-6 Roberts ER, Roberts CR, Duong HT: Chronic insomnia and its negative consequences for health and functioning of adolescents: a 12-month prospective study. J. Adolesc Health 2008;42:294-302.
7 Morphy H, Dunn KM, Lewis M, Boardman HF, Croft PR: Epidemiology of insomnia: a longitudinal study in a UK population. Sleep 2007;30:274-280.

8 LeBlanc M, Mérette C, Savard J, Ivers $\mathrm{H}$, Baillargeon L, Morin CM, et al: Sleep 2009, 32:1027-1037.

-9 Morin CM, LeBlanc M, Daley M, Grégoire JP, Mérette C: Epidemiology of insomnia: prevalence, self-help treatments, consultations, and determinants of help-seeking behaviors. Sleep Med 2006;7:123-130.

$\checkmark 10$ Ohayon MM: Epidemiology of insomnia: what we know and what we still need to learn. Sleep Med Rev 2002;6:97-111.

11 Hornyak M, Kopasz M, Berger M, Riemann D, Voderholzer U: Impact of sleep-related complaints on depressive symptoms in patients with restless legs syndrome. J Clin Psychiatry 2005;66:1139-1145.

12 Allen RP: Finding the dopamine abnormality in RLS: the iron-dopamine connection evaluated in translational research. Sleep Med 2007;8:1-17.
13 Montplaisier J, Nicolas A, Densle R, GomezMancilla B: Restless legs syndrome improved by pramipexole: a double-blind randomized trial. Neurology 1999;52:938-943.

14 Winkelman J, Lichtner P, Trenkwalder C, Hauk S, Meltinger T, Strom T, Müller-Myhsok B: Evidence for further genetic locus heterogeneity and confirmation of RLS-1 in restless legs syndrome. Mov Disord 2006;21: 28-33.

15 Ferini-Strambi L: RLS-symptoms: differential diagnosis by history and clinical assessment. Sleep Med 2007;8:3-6.

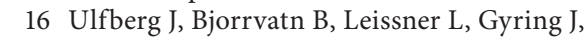
Karlsborg M, Regeur L, et al: Comorbidity in restless legs syndrome among a sample of Swedish adult. Sleep Med 2007;8:768-772.

17 Kotagal S, Silber MH: Childhood-onset restless legs syndrome. Ann Neurol 2004;56: 803-807. 
18 Picchietti DL, Allen RP, Walters AS, Davidson JE, Myers A, Ferini-Strambi L: Restless legs syndrome: prevalence and impact in children and adolescents. The REST Study. Pediatrics 2007;120:253-266.

19 Picchietti DL, Stevens HE: Early manifestations of restless legs syndrome in childhood and adolescence. Sleep Med 2008;9:770-781.

-20 Allen RP, Picchietti D, Hening WA, Trenkwalder C, Walters AS, et al: Restless legs syndrome: diagnostic criteria, special considerations and epidemiology: a report from the Restless Legs Syndrome Diagnosis and Epidemiology Workshop at the National Institutes of Health. Sleep Med 2003;4:101-119.

21 Earley CL: Clinical practice: restless legs syndrome. N Engl J Med 2003;348:21032109.

-22 Picchietti D, Winkelman JW: Restless legs syndrome, periodic limb movements in sleep, and depression. Sleep 2005;28:891898.

23 Winkelman JW: Considering the causes of RLS. Eur J Neurol 2006;13:8-14.

$\checkmark 24$ Lee HB, Hening WA, Allen RP, Kalaydjian AE, Earley CJ, Eaton WW, et al: Restless legs syndrome is associated with DSM-IV major depressive disorder and panic disorder in the community. J Neuropsychiatry Clin Neurosi 2008;20:101-105.

-25 Brand S, Lehtinen A, Hatzinger M, Holsboer-Trachsler E: Comparison of sleep-EEG profiles of patients suffering from RLS, RLS and depressive symptoms, and major depressive disorders. Neuropsychobiology 2010;61: 41-48.

26 Hornyak M: Depressive disorders in restless legs syndrome: Epidemiology, pathophysiology and management. CNS Drugs 2010;24: 89-98.

$\checkmark 27$ Hornyak M, Feige B, Voderholzer U, et al: Polysomnography findings in patients with restless legs syndrome and in healthy controls: a comparative observational study. Sleep 2007;30:861-865.

28 Cho SJ, Hong JP, Hahm BJ, Jeon HJ, Chang SM, Cho MJ, Lee HB: Restless legs syndrome in a community sample of Korean adults: prevalence, impact on quality of life, and association with DSM-IV psychiatric disorders. Sleep 2009,32:1069-1076.

29 Happe S, Reese JP, Stiasny-Kolster K, Peglau I, Mayer G, Klotsche J, et al: Assessing health-related quality of life in patients with restless legs syndrome. Sleep Med 2009;10: 295-305.

30 Costa PT, McCrae RR: Revised NEO Personality Inventory (NEO-PI-R) and NEO FiveFactor Inventory (NEO-FFI). Odessa, Psychological Assessment Resources, 1992.

- 31 Kalaydjian A, Bienvenu OJ, Hening WA, Allen RP, Eaton WW, Lee HB: Restless Legs Syndrome and the five-factor model of personality: results from a community sample. Sleep Med 2009;10:672-675.

- 32 Ondo WG: Restless legs syndrome. Neurol Clin 2009;27:779-799.
33 Kohnen R: The promises of meta-analyses in current RLS research: is $1+1$ more than 2 ? Sleep Med 2008;9:709-711.

- 34 Conti CF, de Oliveira MM, Andriolo RB Saconato H, Atallah AN, Valbuza JS, et al Levodopa for idiopathic restless legs syndrome: evidence-based review. Mov Disord 2007;15:1943-1951.

- 35 Trenkwalder C, Collado Seidel V, Kazenwadel J, Wetter TC, Oertel W, Selzer R, et al: One-year treatment with standard and sustained-release levodopa: appropriate longterm treatment of restless legs syndrome? Mov Disord 2003;18:1184-1189.

-36 Quilici S, Abrams KR, Nicolas A, Martin M, Petit C, Lleu PL, et al: Meta-analysis of the efficacy and tolerability of pramipexole versus ropinirole in the treatment of restless legs syndrome. Sleep Med 2008;9:715-726.

37 Clavadetscher SC, Gugger M, Bassetti CL: Restless legs syndrome: clinical experience with long-term treatment. Sleep Med 2004;5: 495-500.

- 38 Frauscher B, Gschliesser V, Brandauer E, ElDemerdash E, Kaneider M, Rücker L, et al: The severity range of restless legs syndrome (RLS) and augmentation in a prospective patient cohort: association with ferritin levels. Sleep Med 2009;10:611-615.

39 Rechtschaffen A, Kales A: A manual for standardized terminology, techniques and scoring system for sleep stages of human subjects; in Brain Information Service. Los Angeles, Brain Research Institute, NIH Publ No 204, 1968.

40 Lauer CJ, Riemann D, Wiegand M, Berger M From early to late adulthood: changes in EEG sleep of depressed patients and healthy volunteers. Biol Psychiatry 1991;29:979-993.

41 Hautzinger M, Keller F, Kühner C: Beck Depressionsinventar. Göttingen, Hogrefe, 2006.

42 Allen RP, Picchietti D, Hening WA, Trenkwalder C, Walters AS, et al: Restless legs syndrome: diagnostic criteria, special considerations and epidemiology. A report from the Restless Legs Syndrome Diagnosis and Epidemiology Workshop at the National Institutes of Health. Sleep Med 2003;4:101-119.

43 Lee HB, Hening WA, Allen RP, Kalaydjian AE, Earley CJ, Eaton WW, et al: Restless legs syndrome is associated with DSM-IV major depressive disorder and panic disorder in the community. J Neuropsychiatry Clin Neurosi 2008;20:101-105.

44 Bastien CH, Vallières A, Morin CM: Validation of the Insomnia Severity Index (ISI) as an outcome measure for insomnia research. Sleep Med 2001;2:297-307.

45 Hoffmann RM, Rasch T, Schnieder G, et al Fragebogen zur Erfassung allgemeiner Persönlichkeitsmerkmale Schlafgestörter (FEPS-I and II). Göttingen, Hogrefe, 1996.
46 Harvey AG: Pre-sleep cognitive activity: a comparison of sleep-onset insomniacs and good sleepers. Br J Clin Psychol 2000;39: 275-286.

47 Harvey AG: A cognitive model of insomnia. Behav Res Ther 2002;40:869-894.

-48 Brand S, Gerber M, Beck J, Hatzinger M, Pühse U, Holsboer-Trachsler E: High exercise levels are related to favorable sleep patterns and psychological functioning in adolescents: a comparison of athletes and controls. J Adolesc Health 2010;46:133-141.

-49 Brand S, Beck J, Hatzinger M, HolsboerTrachsler E: Perceived parenting styles, personality traits and sleep patterns in adolescents. J Adolesc 2009;32:1189-1207.

50 Buysse DJ, Reynolds CF, Monk TH, Berman SR, Kupfer DJ: The Pittsburgh Sleep Quality Index: a new instrument for psychiatric practice and research. Psychiatry Res 1989; 28:193-213

51 Backhaus J, Riemann D, et al: Schlafstörungen bewältigen. Weinheim, Beltz Psychologie Verlags Union, 1996.

52 Averbeck M, Leiberich P, Grote-Kusch MT, Olbrich E, Schröder A, Brieger M, et al: SEL; Skalen zur Erfassung der Lebensqualität. Pearson, Frankfurt am Main, 1997.

53 Hair JF, Black WC, Babin BJ, Anderson RE. Multivariate Data Analysis. ed 7 Upper Saddle River, Prentice Hall, 2009.

54 Hatzinger M, Hemmeter UM, Brand S, Ising M, Holsboer-Trachsler E: Electroencephalographic sleep profiles in treatment course and long-term outcome of major depression: association with DEX/DRH test response. J Psychiatr Res 2004;38:453-465.

55 Barrière G, Cazalets JR, Bioulac B, Tison F, Ghorayeb I: The restless legs syndrome. Progr Neurobiol 2005;77:139-165.

-56 Rottach KG, Schner BM, Kirch MH, Zivotofsky AZ, Teufel LM, Gallwitz T, Messer T: Restless legs syndrome as side effects of second-generation antidepressants. J Psychiatr Res 2008;43:70-75.

57 Kang SG, Lee HJ, Kim L: Restless legs syndrome and periodic limb movements during sleep probably associated with olanzapine. Part 1. J Psychopharmacol 2009;23:597-601.

58 Kurlan R, Richard IH, Deeley C: Medication tolerance and augmentation in restless legs syndrome: the need for drug class rotation. J Gen Intern Med 2006;21:1-4.

59 García-Borreguero D, Allen RP, Benes $\mathrm{H}$, Earley C, Happe S, Högl B, et al: Augmentation as a treatment complication of restless legs syndrome: concept and management. Mov Disord 2007;18:476-484

-60 Högl B, García-Borreguero D, Kohnen R, Ferini-Strambi L, Hadjigeorgiou G, Hornyak M, et al: Progressive development of augmentation during long-term treatment with levodopa in restless legs syndrome: results of a prospective multi-center study. J Neurol 2010;257:230-237. 
-61 Lautenbacher S, Kundermann B, Krieg JC: Sleep deprivation and pain perception. Sleep Med Rev 2006;10:357-369.

62 Raymond I, Nielsen TA, Lavigne G, Manzini C, Choinière M: Quality of sleep and its daily relationships to pain intensity in hospitalized adult burn patients. Pain 2001;92:381388.

63 Roehrs T, Roth T: Sleep and pain: interaction of two vital functions. Semin Neurol 2005; 25:106-116.

64 Brand S, Gerber M, Pühse U, HolsboerTrachsler E: The relation between sleep and pain among a non-clinical sample of young adults. Eur Arch Psychiatry Clin Neurosci, in press.
65 Aigner M, Prause W, Freidl M, Weiss M, Izadi S, Bach M, et al: High prevalence of restless legs syndrome in somatoform pain disorder. Eur Arch Psychiatry Clin Neurosci 2007;257: 54-57.

66 Buysse DJ, Angst J, Gamma A, Ajdacic V, Eich D, Rössler W: Prevalence, course, and comorbidity of insomnia and depression in young adults. Sleep 2008;31:473-480.

67 Patterson GR, DeBaryshe BD, Ramsey E: A developmental perspective on antisocial behavior. Am Psychol 1989;44:329-335.

68 Pearson VE, Allen RP, Dean T, Gamaldo CE, Lesage SR, Earley CJ: Cognitive deficits associated with restless legs syndrome (RLS). Sleep Med 2006;7:25-30.

-69 Werner H, Molinari L, Guyer C, Jenni OG: Agreement rates between actigraphy, diary, and questionnaire for children's sleep patterns. Arch Pediatric Adolesc Med 2008;162 350-358.
70 Wolfson AR, Carskadon MA, Acebo C, Seifer R, Fallone G, Labyak SE, et al: Evidence for the validity of a sleep habits survey for adolescents. Sleep 2003;26:213-216.

71 Brand S, Beck J, Gerber M, Hatzinger M, Holsboer-Trachsler E: Evidence of favorable sleep-EEG patterns in adolescent male vigorous football players compared to controls. World J Biol Psychiatry 2010;11:465-475.

72 Brand S, Gerber M, Beck J, Hatzinger M, Pühse U, Holsboer-Trachsler E: Exercising, sleep-EEG patterns, and psychological functioning are related among adolescents. World J Biol Psychiatry 2010;11:129-140.

73 Benes H, von Eye A, Kohnen R: Empirical evaluation of the accuracy of diagnostic criteria for restless legs syndrome. Sleep Med 2009;10:524-530. 